\title{
FURTHER EVIDENCE FOR SUPPORTING CELL CONVERSION IN THE DAMAGED AVIAN BASILAR PAPILLA
}

\author{
HENRY J. ADLER,* MOTOTANE KOMEDA* and YEHOASH RAPHAEL* $\dagger$ \\ ${ }^{*}$ Kresge Hearing Research Institute, University of Michigan Medical School, 9301 MSRB III, \\ 1150 West Medical Center Drive, Ann Arbor, U.S.A.
}

\begin{abstract}
Two lines of evidence suggested that a process other than supporting cell divisions may give rise to new hair cells in the bird inner ear injured by either noise or ototoxic drugs. This process, supporting cell conversion, occurs when non-dividing supporting cells transdifferentiate into hair cells. First, noise-exposed chicks received zero, one or two daily i.p. injections of cytosine arabinoside (a DNA synthesis blocker), as well as two daily intraperitoneal injections of bromodeoxyuridine, for four days. Following sacrifice, the papillae were processed for bromodeoxyuridine immunocytochemistry. All the ears demonstrated dividing cells, but increasing the number of cytosine arabinoside injections decreased the number of labeled cells. Indeed, two cytosine arabinoside injections per day nearly completely blocked supporting cell divisions in the short hair cell region within the sound-induced lesion. This suggested that unpaired, immature cells observed in a similar region with scanning electron microscopy, despite the presence of cytosine arabinoside, may have been products of supporting cell conversion. In the second experiment, birds were treated with gentamicin for three days. Upon sacrifice at 6 days post-treatment, papillae were processed for light and transmission electron microscopy. Several unusual cells were observed with phenotypic features of both hair cells and supporting cells. The peculiar cells may be in a transition from the supporting cell phenotype to that of a hair cell. (C) 1997 ISDN
\end{abstract}

Key words: chick; hair cell; supporting cell; mitosis; transdifferentiation; noise; ototoxicity.

When hair cell regeneration was first reported in the chick basilar papilla after intense sound exposure ${ }^{9}$ or ototoxicity, ${ }^{10}$ the myth that higher vertebrates (i.e. mammals and birds) cannot repair their ears crumbled, albeit not completely. The hope that avian hair cell replacement has given the hearing impaired and their loved ones, has greatly encouraged extensive research on the mechanisms of hair cell replacement, which remain to be determined. Tritiated thymidine and bromodeoxyuridine (BrdU) studies revealed new cells in the avian basilar papilla following acoustic or ototoxic trauma. ${ }^{8.14,15,19-21,24-27}$ Moreover, observations of mitosis in supporting cells implicated them as progenitors of new hair cells. ${ }^{20,21,27}$ During a symmetric mitotic process, daughter cells become a pair of hair cells (Fig. 1) or supporting cells, while asymmetric mitosis results in a hair cell and a supporting cell. ${ }^{8,14,15,19-21,24-27}$

A second mechanism of hair cell replacement, called supporting cell conversion, was first suggested by transmission electron microscopic (TEM) observations of unusual cells that were observed in the short hair cell region of the chick basilar papilla immediately after a $10-\mathrm{hr}$ exposure to an intense pure tone (Fig. 2,2,22 compare to Fig. 3). The unusual cells traverse from the reticular lamina to the vicinity of the basilar membrane, a characteristic of supporting cells. ${ }^{2,22}$ However, several other structural aspects of the peculiar cells were characteristic of hair cells, and these aspects included a dense cytoplasm and villi that appeared to be stereocilia. It is important to note that the time used to expose the birds to intense sound prior to the processing of their papillae for TEM was considerably less than the minimal time $(18 \mathrm{hr}$ ) required for any mitotic processes among the supporting cells. ${ }^{27}$ The blend of the characteristics of both hair cells and supporting cells in the unusual cells suggested that the cells were non-dividing supporting cells in the process of transdifferentiating into hair cells.

†To whom correspondence should be addressed. Tel.: 313-936-9386; Fax: 313-647-2563; E-mail: yoash@umich.edu.

Abbreviations: Ara-C, cytosine arabinoside; BrdU, bromodeoxyuridine; SEM, scanning electron microscope; TEM, transmission electron microscope; LM, light microscope; IP, intraperitoneal; PFA, paraformaldehyde. 


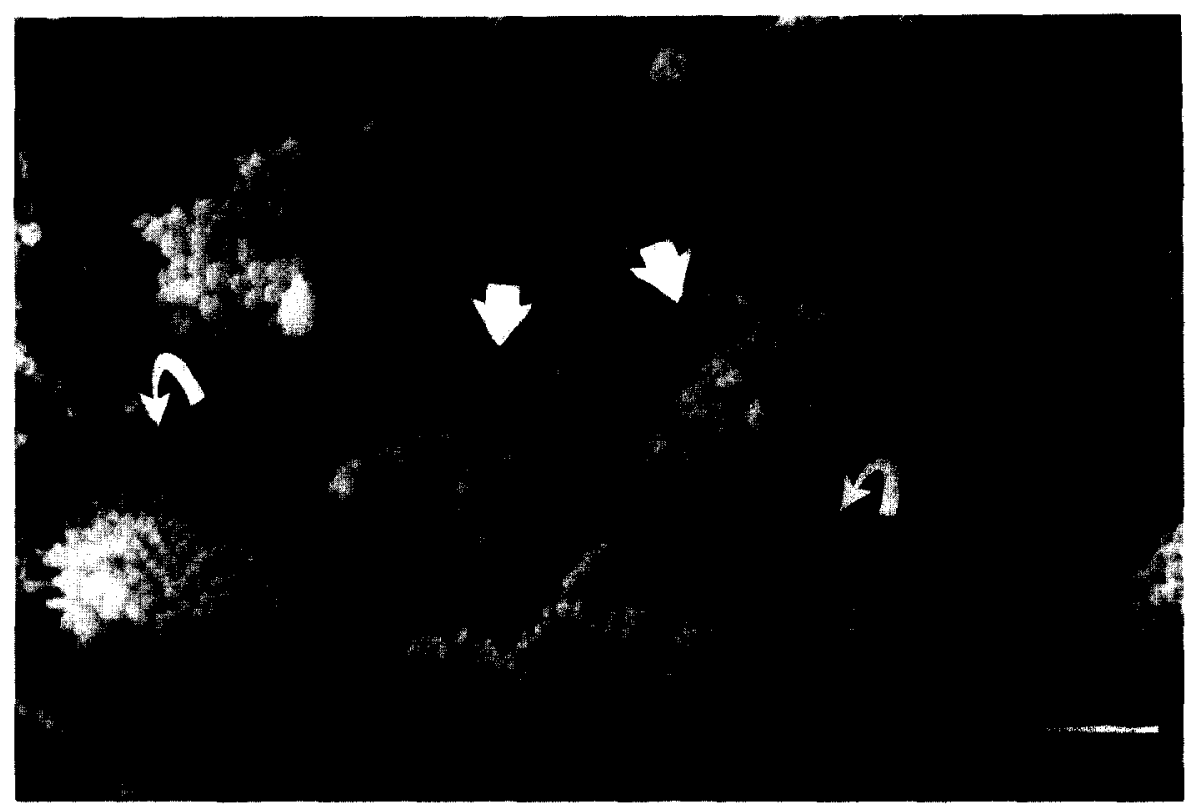

Fig. 1. Numerous pairs of immature hair cells (arrows) are observed at 4 days after acoustic overstimulation The hair cells are paired on the basis of equal apical surface area, same stereociliary orientation, and same make-up of stereocilia and microvilli. Scale bar $=2 \mu \mathrm{m}$.
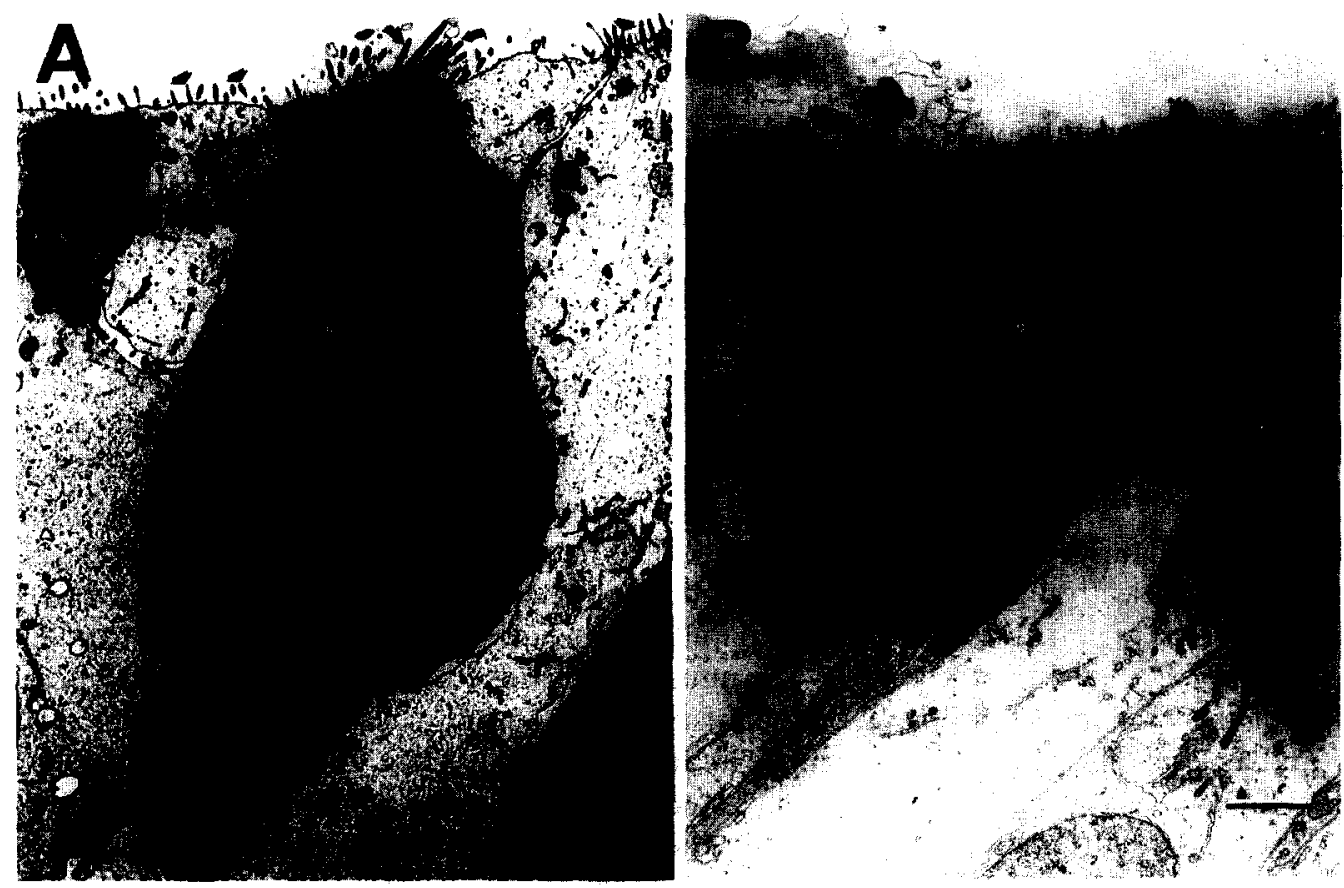

Fig. 2. TEM micrographs of the short hair cell region within the basilar papilla after $10 \mathrm{hr}$ exposure to an intense pure tone. (A) A cell with a dense cytoplasm extends from the reticular lamina to the basilar membrane and is surrounded by supporting cells with a lighter cytoplasm. The darker cell displays villi (curved arrows), some of which appear thicker than supporting cell microvilli (short arrows). Two nuclei (n) are present in this cell. The interval between the onset of exposure and TEM processes did not permit sufficient time for any mitotic process to occur. ${ }^{27}$ Thus, the two nuclei in the peculiar cell may be a result of a fusion of two cells, forming a syncytium. (B) The apical and basal portions of the cell are expanded and narrow, respectively. Note that the unusual cell is adjacent to or in contact with at least two hair cells (h) with dense cytoplasm and stereocilia and one supporting cell (s) with lighter cytoplasm and microvilli. Scale bar =

$2 \mu \mathrm{m}$. (Reprinted from Adler and Raphael, ${ }^{2}$ with kind permission from Elsevier Science Ireland Ltd.) 


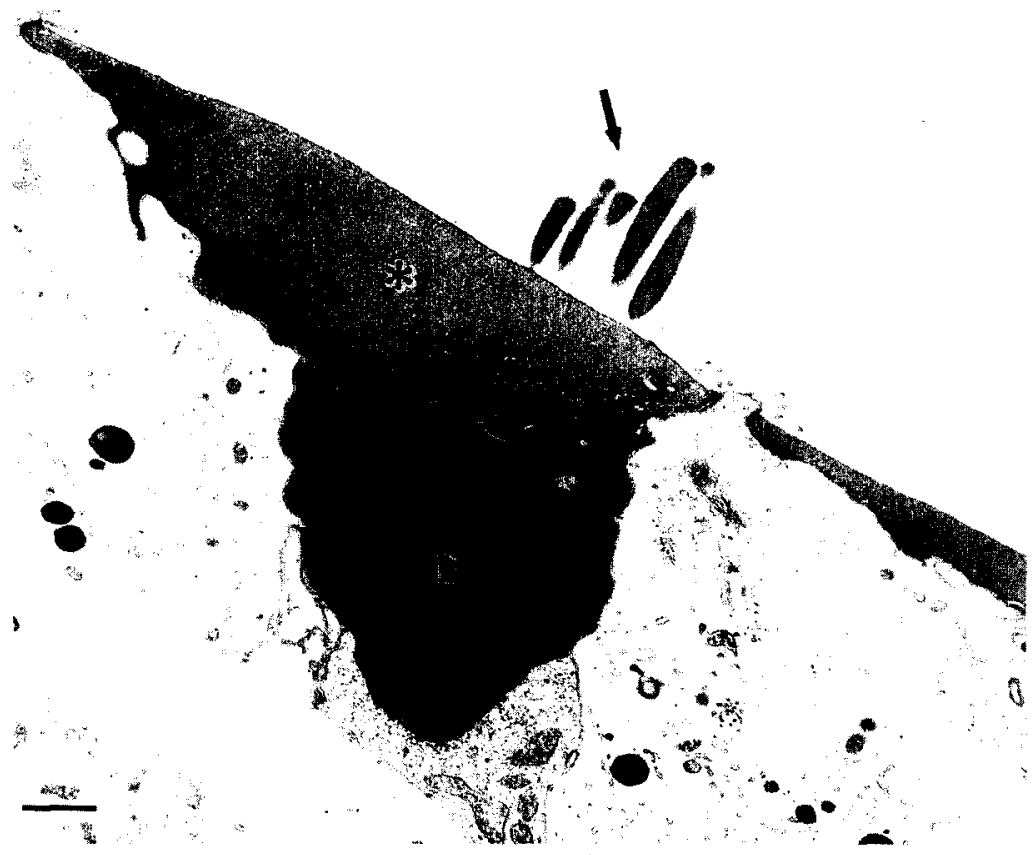

Fig. 3. The TEM image of a normal short hair cell. Stereocilia (arrow) are located superior to the cuticular plate (asterisk), while the nucleus (n) is situated at the basal portion of the hair cell. For further details on chick hair cell morphology, see Brix et al.,${ }^{7}$ Fischer, ${ }^{13}$ and Tanaka and Smith. ${ }^{28}$ Scale bar $=1 \mu \mathrm{m}$.

Since then, several lines of evidence have been presented, supporting conversion. In the present study, two investigations were performed. One of them involved the application of a DNA synthesis blocker, cytosine arabinoside (Ara-C), into chicks following acoustic overstimulation. In our previous study, Ara-C was injected intraperitoneally (i.p.) or intraotically to block supporting cell mitosis in the bird. ${ }^{2}$ Several days after a single, direct Ara-C injection into the ear or after several daily i.p. injections of Ara-C, SEM examinations revealed several immature hair cells in the short hair cell region (Fig. 4). ${ }^{2}$ These immature cells appeared as singles (Fig. 4), unlike those that appeared in pairs in control ears (Fig. 1). The observations suggested that the immature hair cells may have arisen from non-dividing supporting cells. In spite of such promise, further study was necessary to strengthen the support for supporting cell conversion because, at that time, it was not certain whether the single, immature hair cells were the product of conversion or asymmetric supporting cell mitosis. To resolve this dilemma, the first of the two experiments in the present study involved bromodeoxyuridine (BrdU) immunocytochemistry of the acoustically damaged basilar papilla, following i. p. injections of BrdU and/or Ara-C. The immunocytochemical data displayed numerous BrdU-labeled cells in the basilar papilla despite the presence of Ara-C, indicating that Ara-C may not be able to block several supporting cells from dividing. However, most labeled cells were located in the tall-intermediate hair cell region, whereas the earlier SEM observations of single, immature hair cells occurred in the short hair cell (abneural) region. ${ }^{2}$ The nearly complete lack of labeled cells in the abneural region suggested that supporting cell conversion may give rise to the single, immature hair cells. ${ }^{2}$ Portions of this experiment and its results have been presented previously elsewhere, ${ }^{3}$ and are described further in the present paper.

The second investigation involved the use of aminoglycosides to injure the chick basilar papilla. Light microscopic and TEM observations of damaged basilar papillae have revealed cells with a mixed (hair cell-supporting cell) phenotype, similar to those observed by Raphael and Miller after acoustic overstimulation. ${ }^{22}$ Even though these findings are only preliminary and are complementary to the observations of Roberson et al. ${ }^{24}$ they are significant, because they suggest that supporting cell conversion can occur in the bird inner ear after either acoustic overstimulation or ototoxicity. The ototoxicity experiments and their data are described in the present paper. 

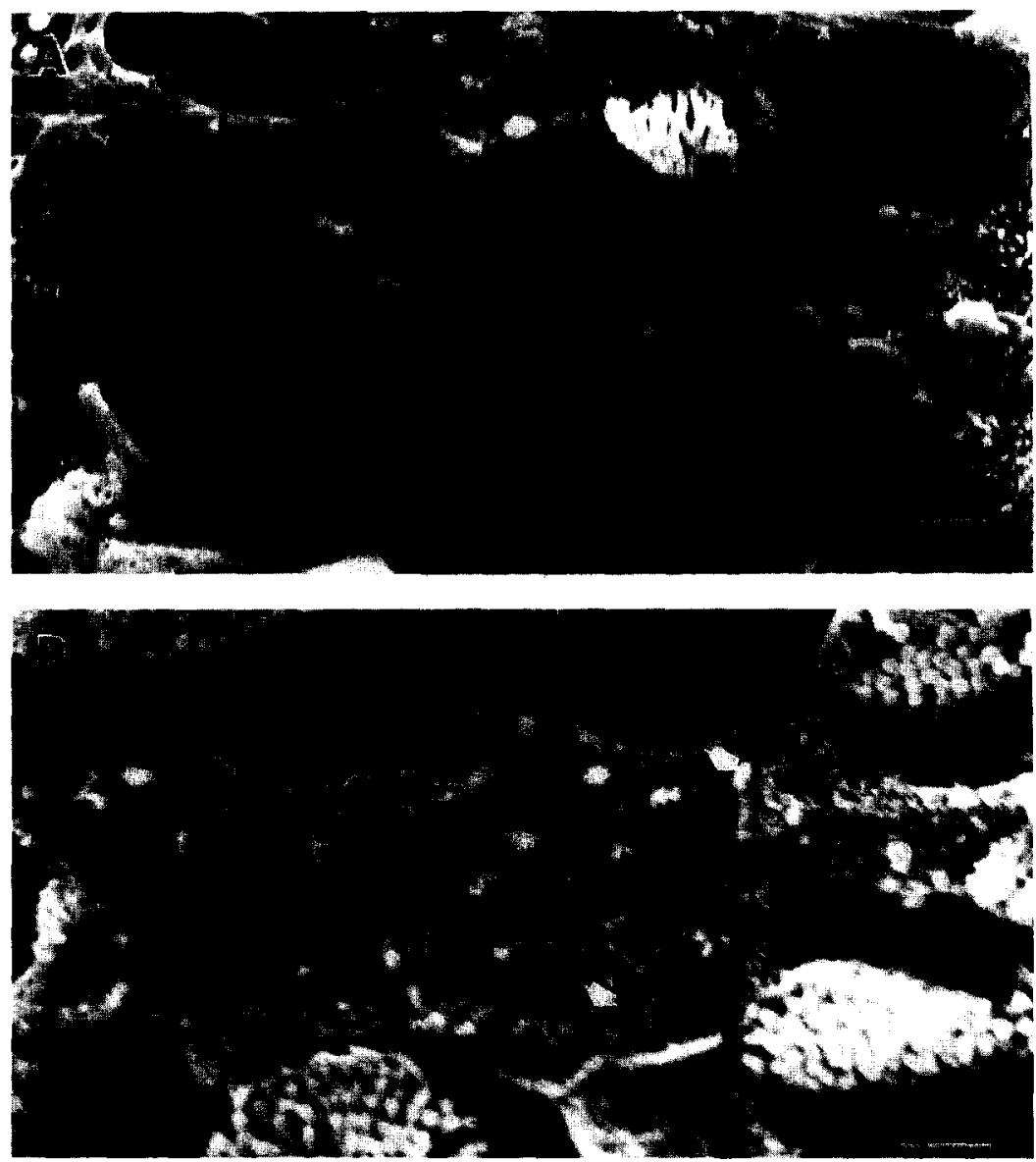

Fig. 4. (A) Five days after intraotic Ara-C injection into the acoustically injured ear, the epithelium displays several surviving hair cells and supporting cells. The stereocilia of the surviving hair cells are deformed (white asterisk). The supporting cells display expanded luminal surfaces. The superior portion of the panel demonstrates a partially regenerated tectorial membrane (black asterisk). Also, the epithelium shows several single new hair cells (white arrowheads). Scale bar $=2 \mu \mathrm{m}$. (Reprinted from Adler and Raphael, ${ }^{2}$ with kind permission from Elsevier Science Ireland Ltd.) (B) Several immature hair cells appear as singles in the acoustically injured papilla following daily IP injections of Ara-C. All of the immature hair cells are located in the short hair cell region. Scale bar $=2 \mu \mathrm{m}$.

\section{EXPERIMENTAL PROCEDURES}

\section{Acoustic overstimulation}

White Leghorn chicks (Gallus domesticus, $1-4$ weeks of age) were divided into three groups (each of which contained four subjects) based on the number of i.p. injections of Ara-C (zero, one, or two injections).

The animals had single i.p. injections of $\mathrm{BrdU}$ and/or Ara-C, prior to acoustic overstimulation, in order for Ara-C to affect the mitotic ability of supporting cells. Both BrdU and Ara-C were obtained from SIGMA (St Louis, U.S.A.), and their doses per injection were $25 \mathrm{mg} / \mathrm{kg}$ weight. Within $15 \mathrm{~min}$ of the injection, the subjects were exposed to an octave band noise with a center frequency of $1.5 \mathrm{kHz}$ at $116 \mathrm{~dB}$ sound pressure level, relative to $20 \mu \mathrm{Pa}$, for $6 \mathrm{hr}$. Further details of exposure conditions have been described elsewhere. ${ }^{1}$

The day after the exposure, all groups had two daily i.p. injections of BrdU. The Ara-C/BrdU groups received one or two daily injections of Ara-C. The day after the last injection, the animals were anesthetized with $35 \%$ chloral hydrate $(0.1 \mathrm{ml} / 100 \mathrm{~g}$ weight $)$ and perfused intracardially with $0.1 \mathrm{M}$ phosphate buffer, followed by $4 \%$ phosphate-buffered paraformaldehyde (PFA; pH 7.3). The birds were decapitated, and their temporal bones removed. The basilar papillae were exposed upon removal of the columella, and were fixed in 4\% PFA for $2-3 \mathrm{hr}$. Following the fixation, the papillae were dissected free of bone. The tegmentum vasculosum and tectorial membrane were removed. 
The ears were pretreated with $2 \mathrm{~N} \mathrm{HCl}$ and $0.15 \%$ Triton $\mathrm{X}-100$ for $30 \mathrm{~min}$. After several washes in $0.15 \%$ Triton $\mathrm{X}-100$, the papillae were incubated overnight in rat antibodies against BrdU (diluted $100 \times$ in $0.15 \%$ Triton X-100) at room temperature (RT). Following several further washes in $0.15 \%$ Triton $\mathrm{X}-100$, the specimens were incubated in goat $\alpha$ rat antibodies (diluted $200 \times$ in $0.15 \%$ Triton X-100) at RT for $30 \mathrm{~min}$. The ears were rinsed again several times in $0.15 \%$ Triton $\mathrm{X}-100$ and then incubated in avidin + biotin complex (Vectastain, Vector Laboratories, Burlingame, CA, U.S.A.) for $30 \mathrm{~min}$. During incubation with the preformed complex, the goat $\alpha$ rat antibodies were conjugated with avidin. Following several $0.15 \%$ Triton X-100 washes, the papillae were crossreacted with a diaminobenzidine-hydrogen peroxidase reaction for $10 \mathrm{~min}$. After several phosphatebuffered saline washes, the ears were mounted on bridged slides and cover-slipped with glycerin as a preservative. The ears were examined under an optical stereo microscope (Leica MZ12).

For statistical comparison among the experimental groups, BrdU-labeled cells were counted within the lesion area in each papilla. One-way analyses of variance (ANOVA) were performed to indicate whether the quantities of marked cells were significantly different $(P<0.05)$.

Two bird groups acted as non-exposed control. One of them received both Ara-C and BrdU, while the other had only BrdU. Following sacrifice, the ears were treated in the same way as those exposed to noise. The controls served to indicate whether Ara-C or BrdU can induce damage in the non-stimulated papilla.

\section{Ototoxic treatment}

Chicks (2-3 weeks old) received a single subcutaneous injection of gentamicin $(200 \mathrm{mg} / \mathrm{kg})$ per day for 3 days, and were allowed to recover for 6 days.

At the end of the survival period, the birds were decapitated. Their basilar papillae were exposed and fixed in 4\% PFA and $0.5 \%$ glutaraldehyde for $1 \mathrm{hr}$. Ears were post-fixed in $1 \% \mathrm{OsO}_{4}$ for $20 \mathrm{~min}$, dehydrated in increasing ethanol concentrations, embedded in EMbed 812 (Electron Microscopy Sciences, Ft Washington, PA, U.S.A.), and sectioned with a glass knife on a Reichert-Jung Ultracut E ultramicrotome. Semi-thin sections were stained with toluidine blue and examined with a light microscope (LM). Once target cells were observed and photographed with a Leitz Dialux microscope, the specimens were further sectioned every $1 \mu \mathrm{m}$ with a diamond knife. The ultrasections were placed on copper grids and stained in $2 \%$ uranyl acetate for $20 \mathrm{~min}$ and in lead citrate for 10 min. The sections were examined with a Phillips COM-100 transmission electron microscope (TEM).

\section{RESULTS}

\section{Acoustic overstimulation}

After BrdU immunocytochemistry, non-exposed control papillae lacked any dividing cells within the reticular lamina region (data not shown). In only one papilla, one pair of BrdU-labeled cells were observed in the hyaline cell region located inferior to the reticular lamina (data not shown). The SEM and fluorescent images of the non-exposed ears also revealed that the papilla retained its normal surface appearance (data not shown). The lack of dividing cells or changes in surface appearance indicated that neither BrdU nor Ara-C had any effect on the non-stimulated basilar papilla.

Figure 5(A) and (B) present whole mounts of basilar papillae that received zero and two i.p. injections of Ara-C, respectively. Both groups demonstrated BrdU-labeled cells with dividing nuclei [Fig. 5(A) and (B)] as did the group that received a single daily injection of Ara-C (data not shown). In the papillae that received BrdU only, BrdU-labeled cells tended to be distributed thoroughly throughout the lesion area [Fig. 5(A)]. The ears that received both Ara-C and BrdU demonstrated a limited distribution of labeled cells. These cells were limited mainly to the tall-intermediate hair cell region [Fig. 5(B)].

Figures 6 and 7 plot the number of BrdU-labeled cells against the number of daily i.p. injections of Ara-C. While Fig. 6 consists of labeled cells throughout the lesion region, in Fig. 7 labeled cells were identified in only the short hair cell region, which occupied the inferior two thirds to three quarters of the lesion area. A one-way ANOVA yielded significant variance in hair cell counts among 

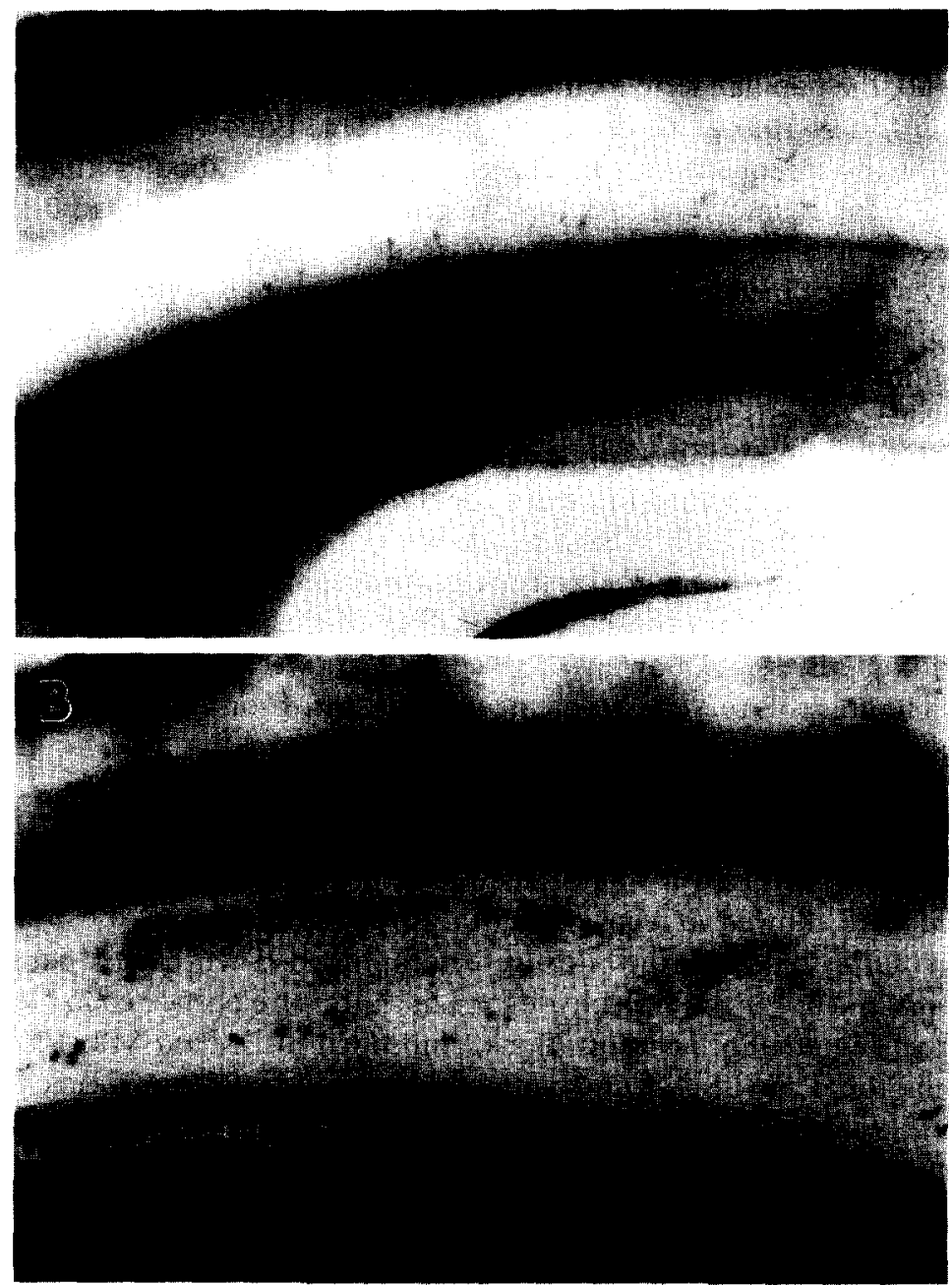

Fig. 5. (A) Whole mounts of acoustically damaged ears that received only BrdU reveal numerous labeled nuclei. The marked cells appear throughout the lesion area. (B) Whole mounts of acoustically damaged ears treated with two daily injections of Ara-C. They exhibit BrdU-labeled cells, but the cells were not as numerous as those in Panel A. The distribution of the labeled cells is limited mainly to the tall-intermediate hair cell region. Scale bar $=200 \mu \mathrm{m}$.

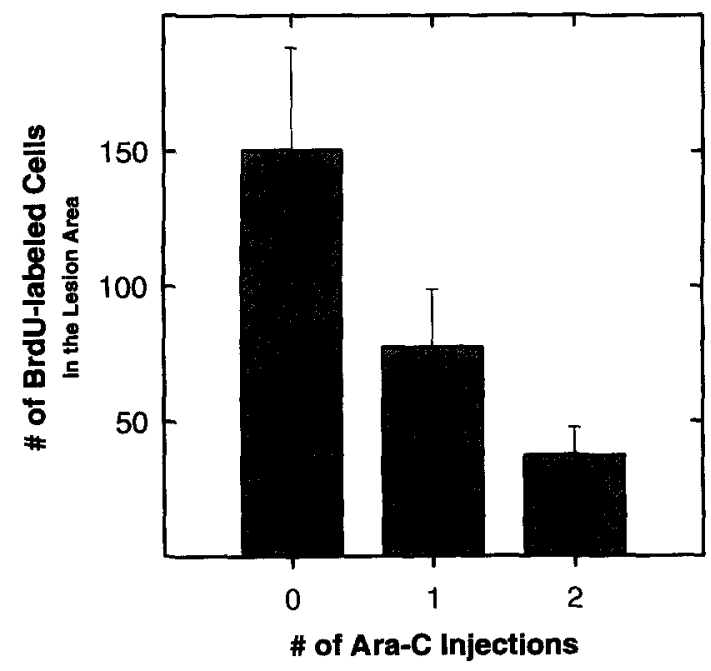

Fig. 6. The number of BrdU-labeled cells in the lesion area is plotted as a function of the number of IP injections of Ara-C. As the number of Ara-C injections increase, the number of labeled cells decrease. In this figure, as well as Fig. 7, error bars represent standard errors. 


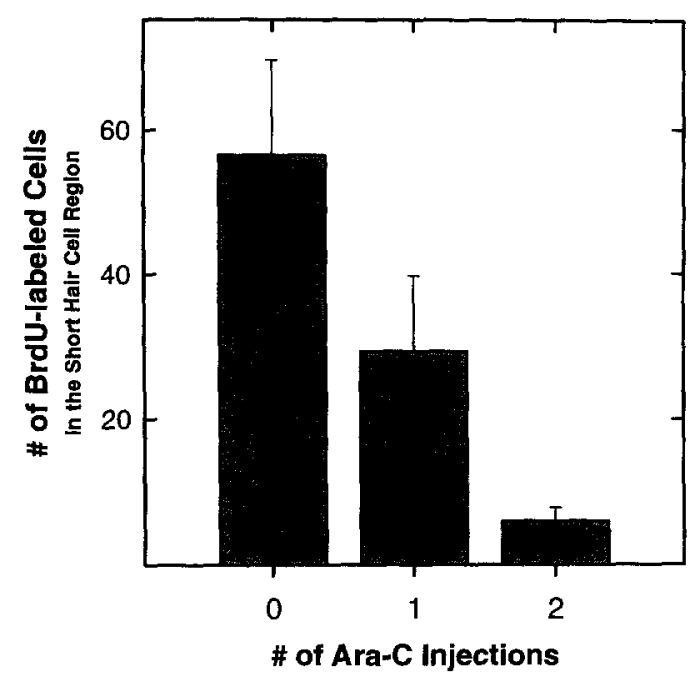

Fig. 7. The plot is similar to Fig. 6, except that the cells were counted in the short hair cell region within the lesion. Note that BrdU labeling is minimal in the short hair cell region after two daily Ara-C injections.

experimental groups (Fig. 6: $H=6.29, \mathrm{df}=2,19, P<0.05$; Fig. $7: H=11.2, \mathrm{df}=2,19, P<0.01$ ). This indicates that the number of BrdU-labeled cells decreases with an increasing number of Ara-C injections. It is noteworthy that BrdU labeling nears zero in the short hair cell region after two daily Ara-C injections (Fig. 7).

\section{Ototoxic treatment}

Figure 8 depicts one of several elongated cells in the tall hair cell region at TEM level. These cells appeared to traverse from the reticular lamina to the vicinity of the basilar membrane. Both microvilli and stereocilia appeared on the apical surface of the cell. In addition, the cytoplasm was more dense than that of surrounding supporting cells. The characteristics were morphologically similar to those in the peculiar cells depicted in Fig. 2.

\section{DISCUSSION}

The present paper demonstrates two sets of results that provide support for the mechanism of hair cell regeneration first reported six years ago. ${ }^{22}$ One set of data presents evidence that Ara-C blocks supporting cell mitosis following acoustic trauma, while the other set displays several elongated cells with both hair cell and supporting cell characteristics at both LM and TEM levels following gentamicin poisoning.

\section{Acoustic overstimulation}

The number of BrdU-labeled cells decreases as the number of Ara-C injections increases (Figs 6 and 7). This suggests that increasing amounts of Ara-C block the mitotic ability of more supporting cells in the chick basilar papilla following acoustic overstimulation. Even though cells with new DNA appeared in the lesion area following two daily injections of Ara-C, the blockage of the mitotic process was nearly complete in the short hair cell region within the lesion area. Recall that the immature hair cells observed at TEM (Fig. 2) and SEM levels (Fig. 4) were located in the short hair cell region. By associating the single hair cells with the near lack of BrdU labeling in the short hair cell region, the immature hair cells may be a product of supporting cell conversion. However, the association between the BrdU immunocytochemical and SEM data needs further work for several reasons. Firstly, and obviously, BrdU-labeled cells appeared in the lesion area despite the presence of Ara-C (Figs 5-7). Ara-C reduced the incidence of Marek's disease, a type of lymphoma that affects chickens. ${ }^{5}$ Since the use of Ara-C was rare in chicks, there was no way of knowing the correct Ara-C concentrations and the correct time of injection in order to block DNA synthesis among supporting cells. Not surprisingly, the less-than-perfect blockage of DNA synthesis by Ara- 


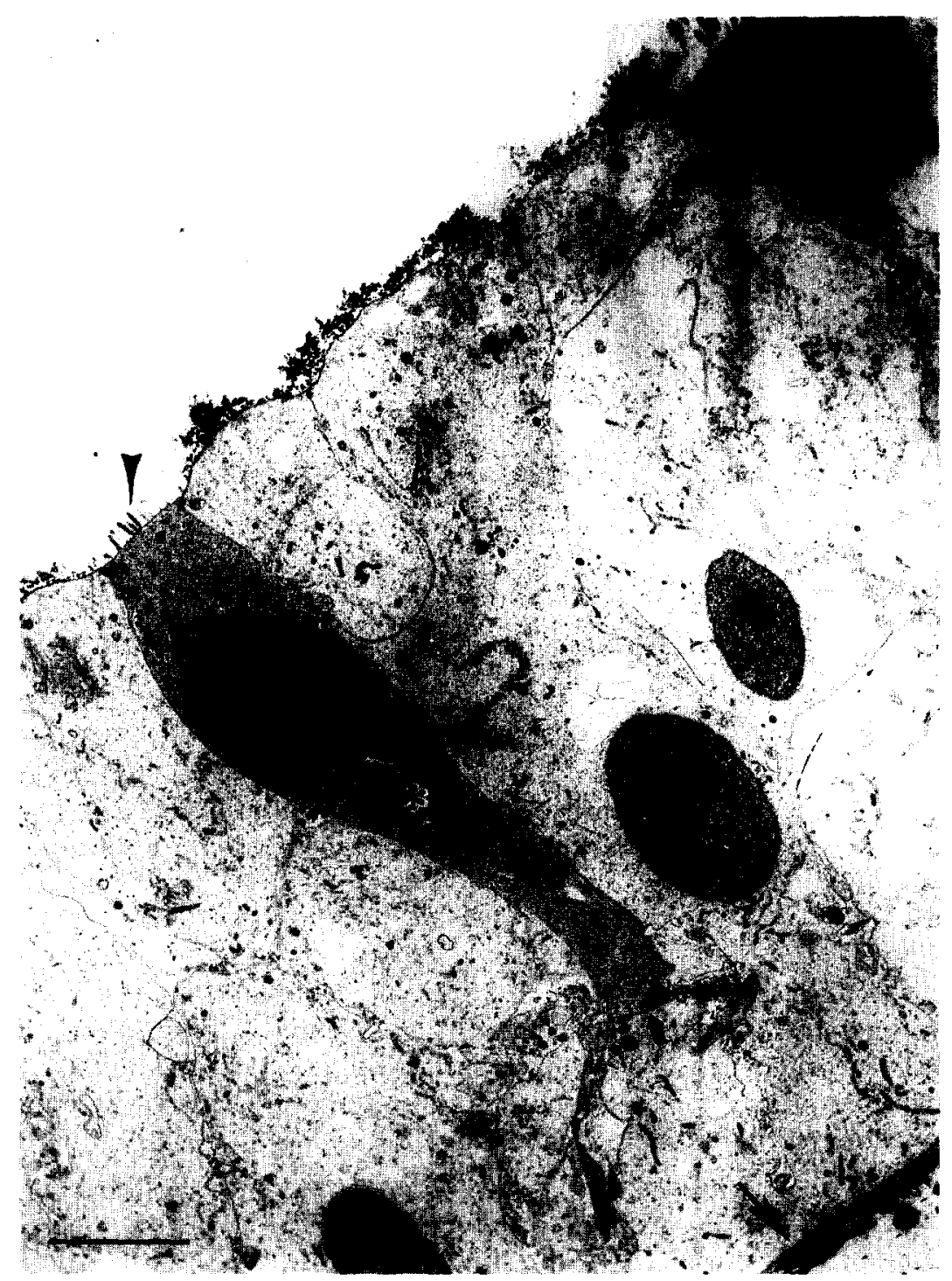

Fig. 8. A cell (asterisk) is depicted in the tall hair cell region 6 days after gentamicin treatment. This cell stretches from the reticular lamina to the area near the basilar membrane (arrow). The elongated cell also depicts a dense cytoplasm and a mixture of microvilli and stereocilia (arrowheads). Also, a nerve fiber is adjacent to the basal end of the cell (curved arrow). Scale bar $=5 \mu \mathrm{m}$.

$\mathrm{C}$ may be due to low Ara-C concentrations in several regions and/or that the time course of the injections of Ara-C and BrdU did not permit enough time for Ara-C to take effect before BrdU incorporation inside supporting cells. Incidentally, Ara-C may miss some supporting cells, which may eventually undergo mitosis. With this in mind, it is possible that the immature hair cells that appeared unpaired (Fig. 4) may be products of an asymmetric division of a supporting cell into a new hair cell and a new supporting cell. Further study is needed to determine the best time to inject Ara-C. in order to work effectively as a blocker of DNA synthesis, to resolve how long it can retain its blocking efficiency, and to apply the right Ara-C concentration for maximum blockage of DNA synthesis during recovery after noise.

The second reason for the uncertainty of the association between the SEM and BrdU studies is that we observed only few elongated cells with dense cytoplasm and a mix of stereocilia and microvilli at either SEM or TEM level following acoustic overstimulation. Due to the rarity of the event, we could not establish the patterns for supporting cell conversion. Also, we could not identify whether the labeled cells in Fig. 5 were hair cells or supporting cells, because we had only the front, not cross-sectional, view of the papilla. It is possible that BrdU may have labeled supporting cells whose nuclei were abnormally dividing as a result of Ara-C altering the mitotic process during $\mathrm{S}$ 
phase. Thus, the identification of unusual cells (Figs 2 and 4) as converting supporting cells needs to be viewed with caution. In order to strengthen the relationship between unlabeled cells (Fig. 5) and single immature hair cells (Figs 2 and 4), the same ears could be processed first for BrdU immunocytochemistry and then for SEM, followed by an analysis of the number of BrdU-labeled cells at the LM level and the number of immature hair cells at the SEM level. However, the rigors of SEM preparation could induce changes and/or damage to the ears, especially those without bone or cartilage support. Another way is to look for peculiar cells at TEM levels following Ara-C treatment.

\section{Aminoglycoside poisoning}

Several peculiar cells were observed spanning from apical surface to vicinity of basilar membrane, and the cell in Fig. 8 is a representative of these cells. Since the morphological characteristics of these cells are similar to those of the unusual cells in Fig. 2, it is possible that the cell in Fig. 8 as well as other similar cells observed following aminoglycoside poisoning, may be supporting cells in the process of converting into hair cells.

It is noteworthy that, in Fig. 8, the cell was appositioned by nerve fibers at the supporting cell nucleus level. This raised the possibility that the cell was a surviving hair cell. However, its cytoplasmic shape differed from that of hair cells, suggesting that the cell in Fig. 8 might be a supporting cell already in the process of converting. If it is definitely a converting supporting cell, it raises a question: what is the role of nerve fibers in initiating and/or modifying the process of supporting cell conversion? Indeed, Wang and Raphael showed that none of the immature hair cells that first appeared 4 days after noise were innervated on the basis of the lack of synapsin labeling ${ }^{30}$ It was only 3 days after the appearance of the first regenerated hair cells (or 7 days after noise) that the immature cells started to have innervation patterns ${ }^{30}{ }^{30}$ This indicates that nerve fibers may have little, if any, effect on hair cell regeneration. ${ }^{30}$

If the cell in Fig. 8 truly is a converting supporting cell, then it may suggest that supporting cell conversion is not limited to the short hair cell region of the injured papilla. Gentamicin caused nearly total hair cell loss and subsequent replacement from the neural to abneural edge of the proximal half of the papilla. ${ }^{24}$ This suggests the loss and regeneration of both tall and short hair cells. ${ }^{24}$ In addition, not all new hair cells were labeled by BrdU, suggesting that the unmarked cells may represent supporting cells in process of directly transdifferentiating into new hair cells. ${ }^{24}$ The question of why supporting cell conversion occurs in only the short hair cell region of the acoustically damaged papilla and in both the short and tall hair cell regions of the ototoxically injured ear remains to be determined. One way of considering this inquiry is that different types of trauma (e.g. ototoxic drugs vs noise) may affect various hair cell regions. For example, supporting cells may respond to the drug-induced loss of both short and tall hair cells, while after exposure to intense sound, supporting cells may tend to replace lost hair cells, most of which are located in the short hair cell region. Recall that the large majority of labeled cells were located in the tall-intermediate hair cell region of the acoustically damaged papilla following Ara-C treatment (Figs 5-7). Whether supporting cell conversion occurs in the tall-intermediate hair cell region after acoustic trauma remains to be seen, but the observation of labeled cells after Ara-C treatment raised the question of why Ara-C could not effectively block supporting cell divisions in the tall-intermediate hair cell region. As mentioned above, the reduced blocking ability may be due to low Ara-C concentrations and/or incorrect timing of Ara-C injections. It is possible also that the poor blocking activity may be due to the fact that supporting cells in the short hair cell region may have a better ability to absorb macromolecules such as Ara-C from blood than those in the tall-intermediate hair cell region. Consequently, the supporting cells may have been affected less by Ara- $\mathrm{C}$ in the tallintermediate hair cell region than in the short hair cell region. These differential reactions by supporting cells in both the short and tall-intermediate hair cell regions in the presence of Ara-C need to be studied further.

\section{Future directions for supporting cell conversion}

The data presented here displayed several uncertainties about the unusual cells being supporting cells in the process of converting into hair cells. To further characterize conversion, it is necessary to study the structural changes that the supporting cells undergo following acoustic or ototoxic trauma. In both Figs 2 and 8, non-dividing supporting cells appear to be expanding in the apical 
surface and shrinking in the basal portion, prior to becoming new hair cells. The cells also appeared to be adjacent to (Figs 2 and 8 ) or in contact with $^{18}$ the basement membrane. On the other hand, the cell cycle of dividing supporting cells following acoustic trauma demonstrates several stages, such as the positioning of the supporting cells and their nuclei on the basement membrane prior to mitosis, the smoothing of the apical surface of the active supporting cell, and nuclear divisions. ${ }^{23}$ The narrowing of the basal portion of the supporting cell on the way to becoming a hair cell appears to represent a different scenario, that of conversion. However, the comparison between the changes of dividing and non-dividing cells is at best speculative, and further study will determine better the changes during supporting cell conversion.

Supporting cell conversion is not limited to birds. Ototoxically damaged bullfrog ${ }^{4,16}$ and guinea pig vestibular organs ${ }^{18}$ demonstrated non-mitotic supporting cells in the process of becoming new hair cells. Those investigations confirmed the suggestions of several investigators that conversion from one cell type to another occurs in numerous mammalian systems. ${ }^{6,11}$ Several questions need to be resolved. For example, what makes supporting cells choose conversion over mitosis and vice versa? What factors are necessary for supporting cell conversion? It is interesting that two possible factors for supporting cell conversion are retinoic acid and calcium-binding proteins. Retinoic acid is a differentiation factor, and was shown to induce an increased number of hair cells of the undamaged mouse organ of Corti. ${ }^{17}$ Calcium-binding proteins were present in both normal hair cells and supporting cells with several hair cell characteristics, but not in the majority of normal supporting cells. ${ }^{16}$ Although growth factors such as IGF-I, TGF- $\alpha$, and bFGF may be important for hair cell regeneration, ${ }^{12,29,31,32}$ their role in supporting cell conversion is unknown. Further study is necessary to clarify the roles of retinoic acid and calcium-binding proteins as well as to determine the role of growth factors in supporting cell conversion.

Acknowledgements-Work was supported by training grant 5 T32 DC 00011 (HJA) and research grant 5 R01 DC01634-03 (YR) from the National Institute on Deafness and Other Communication Disorders. The authors thank the following for their valuable technical help: Jackie Kaufman, Peter Finger, Jennifer Phillips, Keri Van Becelaere, Lynnell Fritsma, Faizah Shabazz, Tara Eisenberg, and Mark Lutz.

\section{REFERENCES}

1. Adler H. J. (1996) Tectorial membrane regeneration in the quail after multiple exposures to intense sound. Audiol. Neurootol. 1, 65-79.

2. Adler H. J. and Raphael Y. (1996) New hair cells arise from supporting cell conversion in the acoustically damaged chick inner ear. Neurosci. Lett. 205, 17-20.

3. Adler H. J., Phillips J. and Raphael Y. (1996) Immunocytochemical evidence for supporting cell conversion in the acoustically damaged chick. Abstr. Assoc. Res. Otolaryngol. 19, 16.

4. Baird R. A., Bales S., Fiorillo C. and Schuff N. R. (1995) In vivo and in vitro evidence for non-mitotic hair cell regeneration in the bullfrog vestibular otolith organs. Assoc. Res. Otolaryng. Abstr. 18, 178.

5. Benda V. (1982) Inhibitory activity of cytosine arabinoside on Marek's disease virus. Fol. Biol. (Praha) 28, 311-315.

6. Beresford W. A. (1990) Direct transdifferentiation: can cells change their phenotype without dividing? Cell Diff. Dev. 29, 81-93.

7. Brix J., Fischer F. P. and Manley G. A. (1994) The cuticular plate of the hair cell in relation to morphological gradients of the chicken basilar papilla. Hear. Res. 75, 244-256.

8. Corwin J. T. and Cotanche D. A. (1988) Regeneration of sensory hair cells after acoustic trauma. Science 240, 17721774.

9. Cotanche D. A. (1987) Regeneration of hair cell stereociliary bundles in the chick cochlea following severe acoustic trauma. Hear. Res. 30, 181-196.

10. Cruz R. M., Lambert P. R. and Rubel E. W (1987) Light microscopic evidence of hair cell regeneration after gentamycin toxicity in chick cochlea. Arch. Otolaryngol. Head Neck Surg. 113, 1058-1062.

11. Eguchi G. and Kodama R. (1993) Transdifferentiation. Curr. Opin. Cell Biol. 5, 1023-1028.

12. Finley J. E. and Corwin J. T. (1995) Assessment of growth factor effects on dissociated hair cell progenitors cultured with a feeder layer. Abstr. Assoc. Res. Otolaryngol. 18, 84.

13. Fischer F. P. (1992) Quantitative analysis of the innervation of the chicken basilar papilla. Hear. Res. 61, 167-178.

14. Hashino E. and Salvi R. J. (1993) Changing spatial patterns of DNA replication in the noise-damaged chick cochlea. $J$. Cell Sci. 105, 23-31.

15. Hashino E., TinHan E. K. and Salvi R. J. (1995) Base-to-apex gradient of cell proliferation in the chick cochlea following kanamycin-induced hair cell loss. Hear. Res. 88, 156-168.

16. Hawkins J. R., Steyger P. S., Schuff N. R. and Baird R. A. (1996) Calcium-binding proteins may be early markers of non-mitotically regenerating vestibular otolith hair cells. Abstr. Assoc. Res. Otolaryngol. 19, 28.

17. Kelley M. W., Xu X.-M., Wagner M. E. and Corwin J. T. (1993) The developing organ of Corti contains retinoic acid and forms supernumerary hair cells in response to exogenous retinoic acid in culture. Development 119, 1041-1053.

18. Li L. and Forge A. (1996) Morphological evidence for the possibility of direct supporting cell to hair cell conversion in the mature mammalian vestibular sensory epithelium. Abstr. Assoc. Res. Otolaryngol. 19, 26. 
19. Lippe W. R., Westbrook E. W. and Ryals B. M. (1991) Hair cell regeneration in the chick cochlea following aminoglycoside toxicity. Hear. Res. 56, 203-210.

20. Raphael Y. (1992) Evidence for supporting cell mitosis in response to acoustic trauma in the avian inner ear. $J$. Neurocytol. 21, 663-671.

21. Raphael Y. (1993) Reorganization of the chick basilar papilla after acoustic trauma. J. Comp. Neurol. 330, 521-532.

22. Raphael Y. and Miller J. M. (1991) Dual mechanisms for production of new hair cells in regenerating avian cochlea. Soc. Neurosci. Abstr. 17, 1214.

23. Raphael Y., Adler H. J., Wang Y. and Finger P. A. (1994) Cell cycle of transdifferentiating supporting cells in the basilar papilla. Hear. Res, 80, 53-63.

24. Roberson D. W., Kreig C. S. and Rubel E. W (1996) Light microscopic evidence that direct transdifferentiation gives rise to new hair cells in regenerating avian auditory epithelium. Audit. Neurosci. 2, 195-205.

25. Ryals B. M. and Rubel E. W (1988) Hair cell regeneration after acoustic trauma in adult Coturnix quail. Science 240, $1774-1776$.

26. Ryals B. M. and Westbrook E. W. (1990) Hair cell regeneration in senescent quail. Hear. Res. 50, 87-96.

27. Stone J. S. and Cotanche D. A. (1994) Identification of the timing of S phase and the patterns of cell proliferation during hair cell regeneration in the chick cochlea. J. Comp. Neurol. 341, 50-67.

28. Tanaka K. and Smith C. A. (1978) Structure of the chicken's inner ear: SEM and TEM study. Am. J. Anat. 153, 251271.

29. Tsue T. T., Oesterle E. C. and Rubel E. W (1994) Diffusible factors regulate hair cell regeneration in the avian inner ear. Proc. natl Acad. Sci. U.S.A. 91, 1584-1588.

30. Wang Y. and Raphael Y. (1996) Re-innervation patterns of chick auditory sensory epithelium after acoustic overstimulation. Hear. Res. 97, 11-18.

31. Warchol M. E. and Corwin J. T. (1993) Supporting cells in avian vestibular organs proliferate in serum-free culture. Hear. Res. 71, 28-36.

32. Xu X.-M. and Corwin J. T. (1993) A protein with TGF $\alpha$-like immunoreactivity is expressed in the cochlea and may be up-regulated during hair cell regeneration. Soc. Neurosci. Abstr. 19, 1579. 